\title{
Evaluation of old-age disability and related factors among an Iranian elderly population
}

M. Adib-Hajbaghery ${ }^{7}$

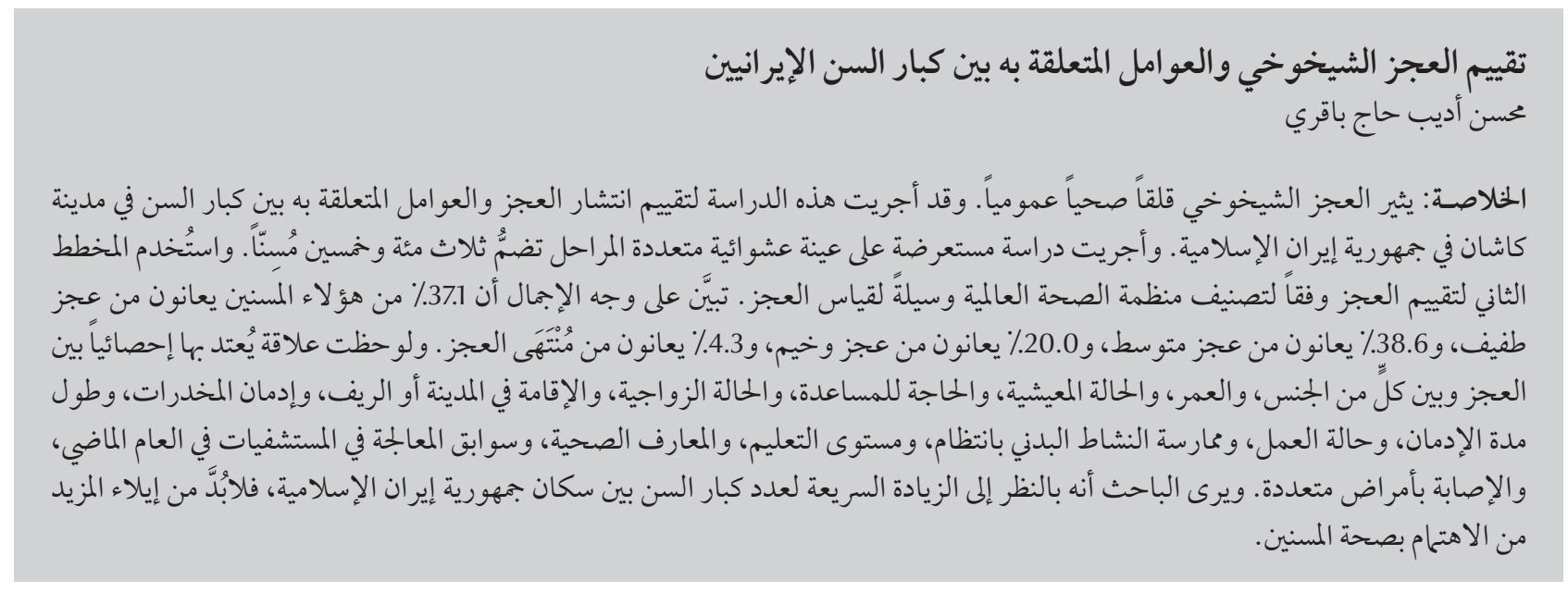

ABSTRACT Old-age disability has become a public health concern. This study was conducted to evaluate the prevalence of disability and its related factors among the elderly population in Kashan city, Islamic Republic of Iran. A cross-sectional study was conducted on a multistage random sample of 350 elderly people. The World Health Organization Disability Assessment Schedule II was used as the disability measure. Overall, $37.1 \%$ had mild ageing disability, 38.6\% moderate, $20.0 \%$ severe and $4.3 \%$ extreme disability. Significant relationships were observed between disability and sex, age, living status, needing help, marital status, urban/rural residence, drug addiction, duration of addiction, employment status, having regular physical activity, level of education, health perception, history of hospitalization in the last year and having multiple diseases. Considering the rapid increase in the aged population in Islamic Republic of Iran, more attention should be paid to the health of elderly people.

Évaluation de l'incapacité liée à l'âge et des facteurs y afférents dans une population de personnes âgées en Iran

RÉSUMÉ L'incapacité liée à l'âge est devenue une préoccupation de santé publique. L'étude a été conduite afin d'évaluer la prévalence de l'incapacité et les facteurs y afférents dans une population de personnes âgées de la ville de Kachan (République islamique d'Iran). Une étude transversale a été menée sur un échantillon aléatoire à plusieurs degrés de 350 personnes âgées. L'échelle OMS pour l'évaluation des incapacités ou WHODAS 2.0 (World Health Organization Disability Assessment Schedule II) a été utilisée pour mesurer l'incapacité. Globalement, 37,1 \% souffraient d'une incapacité liée à l'âge légère, 38,6 \% d'une incapacité modérée, 20,0 \% d'une incapacité sévère et 4,3\% d'une incapacité extrême. Des liens étroits ont été observés entre l'incapacité et le sexe, l'âge, le niveau de vie, le degré de dépendance, la situation matrimoniale, le lieu de résidence urbain ou rural, les toxicomanies et leur durée, la situation professionnelle, la pratique d'une activité physique régulière, le niveau d'études, la perception de la santé, les antécédents d'hospitalisation depuis douze mois et la présence d'affections concomitantes. Étant donné l'augmentation rapide de la population des personnes âgées en République islamique d'Iran, une attention accrue doit être accordée à leur santé. 


\section{Introduction}

Disability has been defined as having a problem in performing any of the activities of daily living, without help or equipment, for 3 months or longer [1]. Disability due to physical, mental or emotional health problems is a major public health issue, resulting in reduction of quality of life and increased dependence on the health care system [2]. Newly developed countries in Asia are ageing faster than other countries. The rate of increase of the elderly population age 65 years and older in these countries is reported to be approximately $3 \%$ annually, compared with $1.0 \%$ to $1.3 \%$ in the United Kingdom, Sweden and the United States [3]. The proportion of people aged 65 years and older in the Islamic Republic of Iran accounted for $6 \%$ of the population in 2005 and it is estimated to reach $19 \%$ by 2030 [4]. The costs associated with disabilities of the elderly are high and continuing to grow $[5,6]$. Therefore, the issue of ageing has precipitated policy discussions around the world $[7,8]$.

The prevalence of disability varies in different countries. Some research literature has indicated an increased trend towards disability in developing countries [3]. Others have suggested that disability is falling among the elderly in developed countries $[1,5]$. Both chronic diseases and acute events such as cardiovascular diseases, stroke, hip fractures, arthritis, skeletal and mobility problems as well as hospitalization are among the most common underlying reasons for physical disability in older adults $[9,10]$. Some reports indicate variations in sex and age in levels of disability $[2,11]$. Parahyba et al. reported a significant relationship between level of disability and age, sex, low education and low income [11].

Studies of the prevalence, causes and effects of disability in ageing populations are crucial for developing an appropriate public health policy in each country. The population of elderly in the Islamic Republic of Iran is increasing rapidly and the government and health care system have not focused on the demands of the elderly as a vulnerable subgroup of society. This study was therefore conducted to evaluate the prevalence of disability and its related factors among the elderly population in Kashan, Islamic Republic of Iran during 2007. The study will enhance health care providers' understanding of elderly disability in this country and similar cultures in Asia and the Middle East.

\section{Methods}

A cross-sectional study was conducted on a random sample of elderly people residing in Kashan city, Islamic Republic of Iran.

\section{Setting and sample}

The study setting and sampling have been described in an earlier paper [12]. The inclusion criteria were age 65 years or older, willing to participate in the study and not having a medical diagnosis of Alzheimer disease. Multistage random sampling was used to select a community sample of 350 people from the estimated population of elderly people in Kashan of 32000 in 2007.

\section{Data collection}

Subjects completed a questionnaire and participated in a formal interview. A 2-part questionnaire was used, as described previously [12]. The first part consisted of questions on sociodemographic characteristics. The second part consisted of a validated Farsi version of the World Health Organization Disability Assessment Schedule II (WHODAS II), which was used as the generic measure of disability in this survey.

\section{Statistical analysis}

A modified version of the WHODAS II Likert scales was used with a maximum score of 144 and the minimum score of 0 (a higher score indicates a lower level of disability). Participants' total scores were categorized as extreme (score $0-36)$, severe (37-72), moderate (73108), mild (109-143) and without disability (144). Descriptive statistics were computed for all variables. Chi-squared test, $\mathrm{t}$-test and analysis of variance were also utilized to analyse the data.

\section{Results}

A total of 350 elderly people (216 males and 134 females) with a mean age of 72.7 [standard deviation (SD) 7.2] years were studied.

Table 1 shows the sociodemographic characteristics and levels of disability of the sample. A majority of the elderly in this sample were illiterate (60.6\%). Most of our subjects had no regular physical activity during their lifetime (77.7\%). A quarter of elderly in this study $(26.0 \%)$ had some addiction/dependency to an opiate, tobacco or psychotropic drug. There were significant differences between men and women in marital status, living status, need for help with activities of daily living, drug addiction, current and previous employment, educational level, health perception and number of diseases/person.

Of the total sample, no one obtained the highest score (no disability), 37.1\% had mild ageing disability, $38.6 \%$ moderate, $20.0 \%$ severe and $4.3 \%$ extreme. There was a significant difference between the sexes in the levels of disability, with $9.0 \%$ of women having extreme disability compared with only $1.4 \%$ of men $(P<0.001)$

The mean score of ageing disability on the WHODAS II was 93.3 (SD 29.9) for the total sample. Table 2 shows that elderly people reported the highest level of disability in the domain of life activities [mean \% of total score was $60.4 \%$ (SD 28.3\%)] and getting around (mobility) [61.9\% (29.2\%)]. The lowest disability was reported in the domain of 


\begin{tabular}{|c|c|c|c|c|c|c|c|}
\hline \multirow[t]{2}{*}{ Variable } & \multicolumn{2}{|c|}{$\begin{array}{l}\text { Females } \\
(n=134)\end{array}$} & \multicolumn{2}{|c|}{$\begin{array}{c}\text { Males } \\
(n=216)\end{array}$} & \multicolumn{2}{|c|}{$\begin{array}{c}\text { Total } \\
(n=350)\end{array}$} & \multirow[t]{2}{*}{$P$-value } \\
\hline & No. & $\%$ & No. & $\%$ & No. & $\%$ & \\
\hline Mean (SD) age (years) & \multicolumn{2}{|c|}{$72.3(7.1)$} & \multicolumn{2}{|c|}{$73.0(7.2)$} & \multicolumn{2}{|c|}{$72.7(7.2)$} & 0.4 \\
\hline Sex & 134 & 38.3 & 216 & 61.7 & 350 & 100.0 & - \\
\hline \multicolumn{8}{|l|}{ Marital status } \\
\hline Married & 69 & 51.0 & 193 & 89.4 & 262 & 74.9 & \multirow{2}{*}{0.001} \\
\hline Widowed & 65 & 49.0 & 23 & 10.6 & 88 & 25.1 & \\
\hline \multicolumn{8}{|l|}{ Living status } \\
\hline Alone & 33 & 24.6 & 9 & 4.2 & 42 & 12.0 & \multirow{4}{*}{0.001} \\
\hline With spouse & 64 & 47.8 & 186 & 86.0 & 250 & 71.4 & \\
\hline With children & 34 & 25.4 & 20 & 9.3 & 54 & 15.4 & \\
\hline With others & 3 & 2.2 & 1 & 0.5 & 4 & 1.2 & \\
\hline \multicolumn{8}{|l|}{ Need help with ADL } \\
\hline Independent & 78 & 58.2 & 179 & 82.9 & 257 & 73.4 & \multirow{2}{*}{0.001} \\
\hline Needing help & 56 & 41.8 & 37 & 17.1 & 93 & 26.6 & \\
\hline \multicolumn{8}{|l|}{ Insurance status } \\
\hline Insured & 105 & 78.4 & 158 & 73.1 & 263 & 75.1 & \multirow{2}{*}{0.31} \\
\hline Noninsured & 29 & 21.6 & 58 & 26.9 & 87 & 24.9 & \\
\hline \multicolumn{8}{|l|}{ Area of residence } \\
\hline Urban & 97 & 72.4 & 171 & 79.2 & 268 & 76.6 & \multirow{2}{*}{0.15} \\
\hline Rural & 37 & 27.6 & 45 & 20.8 & 82 & 23.4 & \\
\hline \multicolumn{8}{|l|}{ Addiction to drugs } \\
\hline Cigarettes & 0 & 0.0 & 36 & 16.7 & 36 & 10.3 & \multirow{4}{*}{0.001} \\
\hline Opiates & 0 & 0.0 & 4 & 1.8 & 4 & 1.1 & \\
\hline Psychotropic drugs & 34 & 25.4 & 17 & 7.9 & 51 & 14.6 & \\
\hline No addiction & 100 & 74.6 & 159 & 73.6 & 259 & 74.0 & \\
\hline $\begin{array}{l}\text { Mean (SD) duration of } \\
\text { addiction (years) }\end{array}$ & \multicolumn{2}{|c|}{$10.4(2.6)$} & \multicolumn{2}{|c|}{$26.4(2.7)$} & \multicolumn{2}{|c|}{$21.3(18.7)$} & 0.001 \\
\hline Current employment stc & & & & & & & \\
\hline Manual worker & 0 & 0.0 & 14 & 6.5 & 14 & 4.0 & \\
\hline Self-employed & 3 & 2.2 & 39 & 18.0 & 42 & 12.0 & ० 001 \\
\hline Retired & 28 & 20.9 & 128 & 59.3 & 156 & 44.6 & 0.001 \\
\hline Other & 103 & 76.9 & 35 & 16.2 & 138 & 39.4 & \\
\hline Previous employment st & & & & & & & \\
\hline Manual worker & 3 & 2.2 & 97 & 44.9 & 100 & 28.6 & \\
\hline Clerk & 0 & & 20 & 9.3 & 20 & 5.7 & 1 $0 \Omega$ م \\
\hline Self-employed & 1 & 0.8 & 61 & 28.2 & 62 & 17.7 & 0.001 \\
\hline Other & 130 & 97.0 & 38 & 17.6 & 168 & 48.0 & \\
\hline Education & & & & & & & \\
\hline Illiterate & 106 & 79.1 & 106 & 49.1 & 212 & 60.6 & \\
\hline Elementary & 27 & 20.1 & 80 & 37.0 & 107 & 30.6 & 0001 \\
\hline Middle grade & 1 & 0.8 & 17 & 7.9 & 18 & 5.1 & 0.001 \\
\hline High school & 0 & 0.0 & 13 & 6.0 & 13 & 3.7 & \\
\hline Regular bodily activity & & & & & & & \\
\hline Yes & 17 & 12.7 & 61 & 28.2 & 78 & 22.3 & 0001 \\
\hline No & 117 & 87.3 & 155 & 71.8 & 272 & 77.7 & 0.001 \\
\hline
\end{tabular}




\begin{tabular}{|c|c|c|c|c|c|c|c|}
\hline \multirow[t]{2}{*}{ Variable } & \multicolumn{2}{|c|}{$\begin{array}{l}\text { Females } \\
(n=134)\end{array}$} & \multicolumn{2}{|c|}{$\begin{array}{l}\text { Males } \\
(n=216)\end{array}$} & \multicolumn{2}{|c|}{$\begin{array}{c}\text { Total } \\
(n=350)\end{array}$} & \multirow[t]{2}{*}{$P$-value } \\
\hline & No. & $\%$ & No. & $\%$ & No. & $\%$ & \\
\hline \multicolumn{8}{|c|}{$\begin{array}{l}\text { Frequency of hospitalizations } \\
\text { (times/last year) }\end{array}$} \\
\hline 0 & 67 & 50.0 & 124 & 57.4 & 191 & 54.6 & \multirow{4}{*}{0.42} \\
\hline $1-2$ & 49 & 36.5 & 67 & 31.0 & 116 & 33.1 & \\
\hline $3-5$ & 13 & 9.7 & 22 & 10.1 & 35 & 10.0 & \\
\hline$>6$ & 5 & 3.73 & 3 & 1.39 & 8 & 2.3 & \\
\hline \multicolumn{8}{|c|}{ Health perception } \\
\hline Excellent & 21 & 15.7 & 16 & 7.4 & 37 & 10.6 & \multirow{5}{*}{0.03} \\
\hline Good & 61 & 45.5 & 90 & 41.6 & 151 & 43.1 & \\
\hline Moderate & 46 & 34.3 & 87 & 40.3 & 133 & 38.0 & \\
\hline Bad & 6 & 4.5 & 22 & 10.2 & 28 & 8.0 & \\
\hline Very bad & 0 & 0.0 & 1 & 0.5 & 1 & 0.3 & \\
\hline \multicolumn{8}{|c|}{ No. of diseases/person } \\
\hline 0 & 15 & 11.2 & 52 & 24.1 & 67 & 19.1 & \multirow[t]{3}{*}{0.001} \\
\hline 1 & 46 & 34.3 & 97 & 44.9 & 143 & 40.8 & \\
\hline $1+$ & 73 & 54.5 & 67 & 31 & 140 & 40.0 & \\
\hline \multicolumn{8}{|c|}{ Level of disability } \\
\hline Extreme & 12 & 9.0 & 3 & 1.4 & 15 & 4.3 & \multirow{4}{*}{0.001} \\
\hline Severe & 47 & 35.1 & 23 & 10.6 & 70 & 20.0 & \\
\hline Moderate & 44 & 32.8 & 91 & 42.1 & 135 & 38.6 & \\
\hline Mild & 31 & 23.1 & 99 & 45.8 & 130 & 37.1 & \\
\hline
\end{tabular}

$S D=$ standard deviation; $A D L=$ activities of daily living .

self-care $[82.7 \%(24.8 \%)]$. The elderly who were in employment after retirement also achieved a higher percentage of the total score than the elderly without self-employment [74.5\% (SD $22.1 \%$ ) versus $69.9 \%$ (SD 21.1\%)].

Table 3 shows the ageing disability score by the sociodemographic characteristics of the elders. A significant relationship was found between ageing disability scores and the following variables: sex, age, living status, needing help, marital status, urban/rural residency, drug addiction (including cigarettes, opiates or psychotropic drugs), duration of addiction, employment status, having regular physical activity, education, having multiple diseases, history of hospitalization and perception of health. However, no significant relation was observed between disability and insurance status. A significant difference was also observed between the disability scores of elderly people with no diagnosed diseases, 1 disease and more than 1 disease.

Table 4 shows the ageing disability score for elders with different diseases. Elderly people with neurological disorders, arthritis and musculoskeletal disorders had the lowest mean scores (i.e. highest levels of disability). The number of chronic diseases per person was also associated with the mean disability score

\section{Discussion}

Around one-quarter (24.3\%) of the elderly people in our sample had extreme to severe disability. The mean score of disability for the whole sample was 93.3, which was indicative of a moderate level of disability in this population of elderly people. The severity of disability increased significantly with increasing age, from a mean score of 99.4 (SD 28.8) in those aged $\leq$ 70 years to 72.6 (SD 35.1) for those aged $91+$ years. The Iranian population of elderly has increased from $1.7 \%$ to more than $6 \%$ within the last 2 decades [4]. Therefore, we can expect that the number of disabled elderly will be further increased in the next decades. There have been no previous studies published on the subject of old-age disability in the Islamic Republic of Iran. However, studies in other countries have shown that approximately $20 \%$ of people aged 70 years or older, and $50 \%$ of people aged 85 years and over, report difficulties in basic activities of daily living [13].

Our analysis showed that the 2 domains of life activities and getting around (mobility) were associated with the highest levels of disability. Scores 


\begin{tabular}{lcccc}
\hline Table 2 Total ageing disability scores in different domains & & & \\
Domain & No. & $\begin{array}{c}\text { Range of } \\
\text { score }\end{array}$ & $\begin{array}{c}\text { Mean (SD) } \\
\text { disability score }\end{array}$ & $\begin{array}{c}\text { Mean (SD) \% of } \\
\text { total score }\end{array}$ \\
Understanding and communicating & 350 & $0-19$ & $18.2(5.9)$ & $75.8(2.4)$ \\
Getting around & & $0-20$ & $12.4(5.8)$ & $61.9(29.2)$ \\
Self care & & $0-16$ & $13.2(4.0)$ & $82.7(24.8)$ \\
Interpersonal interactions & & $0-20$ & $14.6(4.9)$ & $73.1(24.3)$ \\
Life activities & 123 & $0-16$ & $9.7(4.9)$ & $60.4(28.3)$ \\
Working activities & 350 & $0-16$ & $11.1(4.5)$ & $69.3(28.6)$ \\
Participation in society & 123 & $2-32$ & $21.4(7.6)$ & $66.8(23.6)$ \\
Total score (elders with self-employment) & 227 & $6-144$ & $107.3(31.8)$ & $74.5(22.1)$ \\
Total score (elders without self-employment) & & & $89.5(27.0)$ & $69.9(21.1)$ \\
\hline
\end{tabular}

$S D=$ standard deviation.

were highest for those who were independent. This is consistent with the results of Avlund et al., who reported that ageing disability increased the risk of need for home help and nursing home admission [14].

The present study showed that elderly people with neurological diseases, arthritis and musculoskeletal diseases had the highest levels of disability. It seems that diseases with large effects on mobility impose greater levels of disability on old people than cardiovascular diseases for example. Other researchers have also reported that mobility disability is common in elderly people and impedes many activities important to independent living and self-care $[13,15,16]$. Based on our analysis, the number of chronic diseases a person suffered were also associated with the disability scores. Avlund reported that the risk of becoming disabled was 4-fold higher for a person with 4 chronic diseases [17].

We found significant a gender difference in disability severity. The mean disability score was significantly lower for women than men [79.4 (SD 31.8) versus 102.0 (SD 25.1)], which signifies a higher level of disability. It has been shown that women have a longer duration of life lived with disability than men. The reasons for this are still partly unknown, although a higher prevalence of fatal conditions among men and of non-fatal chronic conditions among women has been suggested [18]. Furthermore, women have a lower pulmonary peak capacity function, lower muscle mass and lower bone density and thus, in old age, physiological reserves will be exhausted sooner than in men $[17,19]$.

Most of the elderly in this sample were illiterate and a significant relationship was observed between educational level and disability. The mean disability score of the illiterate elderly was significantly lower than the educated aged people [increasing from 85.5 (SD 30.2) in illiterates to 109.8 (SD 17.0) for those with high school education]. Previous research has also demonstrated that lower education and income were associated with functional decline among elderly men and women $[20,21]$.

We observed a significant difference between the rates of marriage in elderly men and women. Half of elderly women were widowed while $90 \%$ of elderly men were married. Mean scores of disability were also lower in single and widowed elders than the married ones [73.6 (SD 30.2) versus 99.9 (SD 26.9)]. The mean score of disability was also lower in elderly people who lived alone [74.6 (SD 27.2)] than those who lived with their spouses [99.8 (SD 27.3)] or with their children [81.6 (SD 31.7)]. Goldman et al. found that widowed men aged 70 years and over had significantly higher rates of mortality and disability than married men [22]. However, Hewitt et al. reported a weak association between marital status and health for men, but that widowed and never married women had better general health than married and separated women [23]. Other studies have also found that living alone [21] and being widowed [22] were risk factors of disability among men. According to Avlund, older adults with a lack of social relations may be more susceptible to decline than others, and that older disabled women living alone may be at special risk of not recovering from disability [17].

Most of our subjects had not practised regular physical activity during their life. The mean score of disability was also significantly lower in the elderly without regular physical activity. The rate of regular activity was also less in women. This is consistent with finding of Adib and Masoodi who studied the characteristics of patients with hip fractures in Islamic Republic of Iran [24]. Physically inactive people often obtain poorer results in physiological and sensory-motor tests, while the elderly who were physically active in their earlier life maintain a higher level of physiological function [25], good mobility and independence [26] and had a shorter period of disability prior to death [27]. 


\begin{tabular}{|c|c|c|}
\hline \multicolumn{3}{|c|}{$\begin{array}{l}\text { Table } 3 \text { Ageing disability score by sociodemographic characteristics of the elderly } \\
\text { population }\end{array}$} \\
\hline Variable & Mean (SD) disability score & $P$-value \\
\hline \multicolumn{3}{|l|}{ Age (years) } \\
\hline$\leq 70$ & $99.4(28.8)$ & \multirow{4}{*}{0.001} \\
\hline $71-80$ & $90.8(28.7)$ & \\
\hline $81-90$ & $77.7(30.7)$ & \\
\hline $91+$ & $72.6(35.1)$ & \\
\hline \multicolumn{3}{|l|}{ Sex } \\
\hline Male & $102.0(25.1)$ & \multirow{2}{*}{0.001} \\
\hline Female & $79.4(31.8)$ & \\
\hline \multicolumn{3}{|l|}{ Marital status } \\
\hline Married & $99.9(26.9)$ & \multirow{2}{*}{0.001} \\
\hline Widowed & $73.6(30.2)$ & \\
\hline \multicolumn{3}{|l|}{ Living status } \\
\hline Alone & $74.6(27.2)$ & \multirow{4}{*}{0.001} \\
\hline With spouse & $99.8(27.3)$ & \\
\hline With children & $81.6(31.7)$ & \\
\hline With others & $51.0(37.4)$ & \\
\hline \multicolumn{3}{|l|}{ Need help with ADL } \\
\hline Independent & $102.7(25.2)$ & \multirow{2}{*}{0.001} \\
\hline Needing help & $67.4(26.7)$ & \\
\hline \multicolumn{3}{|l|}{ Insurance status } \\
\hline Insured & $94.6(30.6)$ & \multirow{2}{*}{0.17} \\
\hline Noninsured & $89.6(27.9)$ & \\
\hline \multicolumn{3}{|l|}{ Area of residence } \\
\hline Urban & $96.1(30.4)$ & \multirow{2}{*}{0.002} \\
\hline Rural & $84.4(26.6)$ & \\
\hline \multicolumn{3}{|l|}{ Addiction } \\
\hline Cigarette & $101.0(24.7)$ & \multirow{4}{*}{0.005} \\
\hline Opiates & $78.0(42.0)$ & \\
\hline Psychotropic drugs & $81.2(24.5)$ & \\
\hline No addiction & $94.9(30.8)$ & \\
\hline \multicolumn{3}{|c|}{ Duration of addiction (years) } \\
\hline$<4$ & $78.2(28.0)$ & \multirow[t]{2}{*}{0.021} \\
\hline $4+$ & $94.7(26.4)$ & \\
\hline \multicolumn{3}{|l|}{ Present job } \\
\hline Manual worker & $107.7(29.9)$ & \multirow{4}{*}{0.001} \\
\hline Self-employed & $114.4(25.6)$ & \\
\hline Retired & $90.8(27.7)$ & \\
\hline Other & $88.4(30.8)$ & \\
\hline \multicolumn{3}{|l|}{ Previous job } \\
\hline Manual worker & $99.2(26.9)$ & \multirow{4}{*}{0.001} \\
\hline Clerk & $112.6(15.2)$ & \\
\hline Self-employed & $109.8(24.0)$ & \\
\hline Other & 83.9 (31.2) & \\
\hline
\end{tabular}

In the present study, the severity of who continued in self-employment afdisability was lower in elderly people ter retirement than those who did not [mean score 107.3 (SD 31.8) versus 89.5 (SD 27.0)]. It seems that employment after retirement could delay ageing disability by preserving old people's physical and cognitive abilities and keep them socially active. Therefore, flexibility in the definition of age of retirement may help to maintain and improve the quality of life in older age groups.

We found an association between area of residence and ageing disability. The elderly living in rural areas had a lower mean score than the elderly living near to the city centre [84.4 (SD 26.6) versus 96.1 (SD 30.4)]. This contrast with the results of a study conducted in Brazil, in which the elderly living in rural areas had a lower level of disability than those living in urban areas [20]. Our finding is consistent with Allain et al. who reported that the elderly in rural areas in Zimbabwe had more disability than in the urban areas [28]. It seems that the elderly who live in rural areas have more difficulties in transport and access to shopping and health care facilities and they experience greater disability than those who live nearer to the city centre.

About $26 \%$ of elderly in this study had some addiction/dependency to an opiate, tobacco or psychotropic drug. The mean score of elders with addiction to opiates [78.0 (SD 42.0)] were significantly lower than those with no drug use [94.9 (SD 30.8)] or only cigarette smoking [101.0 (SD 24.7)]. Use of opiates and psychotropic drugs could increase unwanted effects (e.g. as confusion, accidental falls, memory decline and behavioural changes) [29] that could be contributed to more severe disability in the drug user elderly. However, those with a longer duration of addiction (4+ years) had a higher mean score (a lower level of disability) than those with $<4$ years addiction [94.7 (SD 26.4) versus 78.2 (SD 28.0)]. This finding is surprising and needs more investigation. However, it is possible that people with longer duration of addiction may have 


\begin{tabular}{lcc}
\hline $\begin{array}{l}\text { Table } 3 \text { Ageing disability score by sociodemographic characteristics of the elderly } \\
\text { population (concluded) }\end{array}$ & & \\
\hline Variable & Mean (SD) disability score & P-value \\
Education & $85.5(30.2)$ & \\
Illiterate & $104.6(27.0)$ & 0.001 \\
Elementary & $107.6(19.6)$ & \\
Intermediate & $109.8(17.0)$ & \\
High school & & \\
Regular bodily activity & $111.7(19.4)$ & \\
Yes & $88.1(30.4)$ & \\
No & & \\
Frequency of hospitalizations & & \\
(times/last year) & $117.5(25.1)$ & \\
0 & $92.8(30.6)$ & \\
$1-2$ & $83.2(30.2)$ & \\
$3-5$ & $76.0(28.3)$ & \\
$6+$ & & \\
Health perception & & \\
Excellent & $66.3(28.8)$ & \\
Good & $87.1(27.6)$ & \\
Moderate & $105.2(24.6)$ & \\
Bad & $107.0(33.5)$ & \\
Very bad & $66.0(0.0)$ & \\
No. of diseases/person & & \\
0 & & \\
1 & & \\
$1+$ & & \\
\hline$-s 6.4(30.7)$ & \\
\hline
\end{tabular}

$S D=$ standard deviation; $A D L=$ activities of daily living.

some coping mechanisms and therefore express fewer complaints.
The highest level of disability was found in the elderly who had been hospitalized more than 6 times in the previous 12 months [mean score 76.0 (SD 28.3)] compared with those with no hospitalizations [117.5 (SD 25.1)]. A relationship between disability and hospitalization and need for home help has also previously reported by Avlund et al. [14,17] and Allain et al. [28].

To the best of our knowledge this is the first published research on disability among the Iranian elderly population. Although different disability measures exist, for this study the researchers selected the WHODAS II questionnaire for its cultural appropriateness and ease of application.

In conclusion, a considerable proportion of the elderly people in our study had extreme or severe disability. Considering the rapid rise in aged populations, more attention should be paid to the health and quality of life of elderly people. Further research is needed for a better understanding of the extent of the problem within the Islamic Republic of Iran. The public and the authorities should pay more attention and provide more support and facilities for elderly women and elderly people who live alone. Public education on the importance of regular physically activity and its continual after the age of retirement may be effective for disability

\begin{tabular}{|c|c|c|c|}
\hline Variable & No. & Mean (SD) disability score & Mean (SD) \% of total score \\
\hline \multicolumn{4}{|l|}{ Disease } \\
\hline Cardiac & 21 & $95.6(31.7)$ & $66.4(22.0)$ \\
\hline Respiratory & 15 & $99.1(29.7)$ & $68.8(20.6)$ \\
\hline Diabetes & 5 & $112.8(9.2)$ & $78.3(6.4)$ \\
\hline Arthritis & 10 & $86.5(36.2)$ & $60.1(25.1)$ \\
\hline Musculoskeletal & 21 & $86.7(25.1)$ & $60.2(17.5)$ \\
\hline Neurological & 7 & $83.3(45.2)$ & $57.8(31.4)$ \\
\hline Hypertension & 16 & $90.3(45.5)$ & $62.7(31.6)$ \\
\hline Hyperlipidaemia & 3 & $113.0(12.5)$ & $7.5(8.7)$ \\
\hline Other & 45 & $103.2(23.7)$ & $71.6(16.4)$ \\
\hline \multicolumn{4}{|c|}{ No. of diseases/person } \\
\hline 0 & 67 & $112.1(23.1)$ & $77.8(16.0)$ \\
\hline 1 & 143 & $96.4(30.7)$ & $66.9(21.3)$ \\
\hline $1+$ & 140 & $81.4(26.7)$ & $56.5(18.6)$ \\
\hline
\end{tabular}

$S D=$ standard deviation. 
prevention in older age. Providing some types of jobs or social activities after the age of retirement and revising the age of retirement may also keep elderly people active and socially engaged and decrease their risk of disability. The relationship of addiction and living in rural areas with the level of disability remained unclear in this research and need more research.

\section{References}

1. Spillman BC. Changes in elderly disability rates and the implications for health care utilization and cost. Milbank Quarterly, 2004, 82:157-194.

2. Larry LS. Disability among adults in New York State, 20012003: prevalence and health risk behavior. Behavioral Risk Factor Surveillance System, 2005, 12(1):1-8.

3. Ng T-P et al. Prevalence and correlates of functional disability in multiethnic elderly Singaporeans. Journal of the American Geriatrics Society, 2006, 54:21-29.

4. Amir-Sadri A, Soleimani H. Elderly phenomena and its outcomes in Iran. International Journal of Hygiene and Health, 2005, 1:19-35.

5. Cutler DM. The reduction in disability among the elderly. Proceedings of the National Academy of Sciences of the United States of America, 2001, 98:6546-6547.

6. Bone M. Trends in dependency among older people in England. London, Office of Population Census and Surveys, 1995.

7. Melzer D et al. Profile of disability in elderly people: estimates from a longitudinal population study. British Medical Journal, 1999, 318:1108-1111.

8. Wiener J. Long term care reform: an international perspective. In Health care reform: the will to change. Paris, Organization for Economic Cooperation and Development, 1996 (Health Policy Studies, No. 8).

9. Fried LP, Guralnik JM. Disability in older adults: evidence regarding significance, etiology, and risk. Journal of the American Geriatrics Society, 1997, 45:92-100.

10. Wilcox VL, Kasl SV, Idler EL. Self-rated health and physical disability in elderly survivors of a major medical event. Journals of Gerontology. Series B, Psychological Sciences and Social Sciences, 1996, 518:S96-S104.

11. Parker CJ, Morgan K, Dewey ME; The Analysis Group. Physical illness and disability among elderly people in England and Wales: the Medical Research Council Cognitive Function and Ageing Study. Journal of Epidemiology and Community Health, 1997, 51:494-501.

12. Adib-Hajbaghery M, Aghahoseini S. The evaluation of disability and its related factors among the elderly population in Kashan, Iran. BMC Public Health, 2007, 7:261.

13. Heikkinen E. Functional capacity and health of elderly peoplethe Evergreen project. Scandinavian Journal of Social Medicine. Supplementum, 1997, 53:1-18.

14. Avlund K, Damsgaard MT, Schroll M. Tiredness as determinant of subsequent use of health and social services among nondisabled elderly people. Journal of Aging and Health, 2001, 13:267-286.
15. Guralnik JM et al. Progressive versus catastrophic loss of the ability to walk: implications for the prevention of mobility loss. Journal of the American Geriatrics Society, 2001, 49:1463-1470.

16. Avlund $\mathrm{K}$ et al. Changes in social relations in old age: Are they influenced by functional ability. Aging Clinical and Experimental Research, 2002, 14S:56-64.

17. Avlund K. Disability in old age: Longitudinal population-based studies of the disablement process. Danish Medical Bulletin, 2004, 51:315-349.

18. Gold $\mathrm{CH}$ et al. Gender and health: a study of older unlike-sex twins. Journals of Gerontology. Series B, Psychological Sciences and Social Sciences, 2002, 57:S168-S176.

19. Leveille SG, Resnick HE, Balfour J. Gender differences in disability: evidence and underlying reasons. Aging, 2000, 12:106-112.

20. Parahyba MI, Veras R, Melzer D. Incapacidade funcional entre as mulheres idosas no Brasil [Disability among elderly women in Brazil]. Revista de Saúde Pública, 2004, 39:383-91.

21. Strawbridge WJ et al. Gender differences in factors associated with change in physical functioning in old age: a 6-year longitudinal study. Gerontologist, 1993, 33:603-609.

22. Goldman N, Koreman S, Weinstein R. Marital status and health among the elderly. Social Science \& Medicine, 1995, 40:1717-1730.

23. Hewitt $\mathrm{B}$ et al. Marriage dissolution and health amongst the elderly: the role of social and economic resources. 2004 (http:// melbourneinstitute.com/downloads/hilda/Bibliography/ wp/hewitt.pdf, accessed 1 August 2011).

24. AdibHajbaghery M, Masoody-Alavi N. Evaluating the patients with osteoporotic neck femor bone fractures in Kashan. Feyz, Kashan University of Medical Sciences and Health Service, 2007, 10:52-58.

25. Rantanen T. Muscle strength, disability and mortality. Scandinavian Journal of Medicine and Science in Sports, 2003, 13:3-8.

26. LaCroix AZ et al. Maintaining mobility in late life. II. Smoking, alcohol consumption, physical activity, and body mass index. American Journal of Epidemiology, 1993, 137:858-869.

27. Leveille SG et al. Aging successfully until death in old age: opportunities for increasing active life expectancy. American Journal of Epidemiology, 1999, 149:654-664.

28. Allain TJ et al. Morbidity and disability in elderly Zimbabweans. Age and Ageing, 1997, 26:115-121.

29. Armour D, Cairns C. Medicines in the elderly. London, Pharmaceutical Press, 2002. 